\title{
Historia conceptual y social del totalitarismo. Una propuesta teórico-metodológica
}

Conceptual and social history of totalitarianism. A theoretical-methodological proposal

\author{
José Javier Blanco-Rivero / joseblanco@usb.ve \\ http://orcid.org/0000-0002-7325-1201 \\ Universidad Simón Bolivar, Venezuela / Centro de Historia Intelectual, Universidad \\ Nacional de Quilmes, Argentina
}

\begin{abstract}
Our goal is to propose a theoretical-methodological approach for the study of Intellectual History in order to provide an explanation of the inter-relationships between social and semantic change translating such reflections into a set of tools for historic research. For that purpose, the distinction semantics/social structure -elaborated by Niklas Luhmann in his sociology of knowledge- is taken and re-described by introducing the distinction between information and meaning. The aforementioned theoretical frame is put to the test by making a sketch of a conceptual and social history of totalitarianism. It will be concluded that the concept of totalitarianism allows accounting for how meaning self-organizes following a historical dynamic of its own, in spite that no meaning at all can be produced out of social systems and the codes they employ to process information. Intellectual history is written simultaneously on both registers of information and meaning.
\end{abstract}

Key words: semantics, social structure, social systems, conceptual history, totalitarianism.

Resumen: Nuestro objetivo es formular una propuesta teórico-metodológica para el estudio de la historia intelectual, capaz de explicar las interrelaciones entre cambio social y cambio lingüístico, traduciendo tales reflexiones en herramientas para la investigación histórica. Para tal fin, tomamos la distinción semántica/estructura social, elaborada por la sociología del conocimiento de Niklas Luhmann y la redescribimos introduciendo la distinción entre información y significado. El mencionado marco teórico es puesto a prueba realizando un bosquejo de la historia conceptual y social del totalitarismo. Llegamos a la conclusión de que el concepto de totalitarismo nos permite dar cuenta de cómo los significados se autoorganizan siguiendo una dinámica histórica propia, aunque ninguna producción de significado puede tener lugar fuera de los sistemas sociales y de los códigos que éstos emplean para procesar información. La historia intelectual se escribe simultáneamente sobre los dos registros de la información y el significado.

Palabras clave: semántica, estructura social, sistemas sociales, historia conceptual, totalitarismo. 


\section{Introducción}

El propósito de este artículo consiste en la exposición de un modelo teórico que pretende responder a un conjunto de inquietudes teórico-metodológicas, surgidas en el seno de la historia intelectual. Se trata de la relación entre lo lingüístico y lo extralingüístico, entre la sociedad y el lenguaje.

Como es bien sabido, en las últimas décadas se ha desarrollado una variedad de propuestas teórico-metodológicas en la historia intelectual, tales como la denominada Escuela de Cambridge, la historia de las mentalidades o representaciones, la genealogía de Michel Foucault y la historia conceptual de Reinhart Koselleck. Por más diversas que sean las tradiciones que las nutren, todas parecen converger en un par de puntos: a) la importancia del lenguaje como factor e indicador del cambio social; y b) el señalamiento de que la historia intelectual se mueve entre dos dimensiones (cuya descripción, naturalmente, varía según el autor): la de los cambios sociales y la de los cambios lingüísticos.

Sin embargo, acá acaban las convergencias. Las formas de describir las relaciones del lenguaje con la sociedad y de interrelacionar teóricamente ambas dimensiones son muy diferentes. En la Escuela de Cambridge, Skinner (1989) aborda el problema desde un punto de vista pragmático: para este autor el acto ilocutivo en su performatividad produce cambios sociales, pues un acto de habla equivale a una acción social. El problema estaría entonces en estudiar las redescripciones retóricas que transforman las convenciones sociales, abriendo paso a nuevos estados de cosas. Por su parte, Pocock (1985, 1987 y 1989) reconoce que existe alguna relación entre los lenguajes políticos y la estructura social; pero vacila al considerar si el tema le compete a la historia intelectual y, en tal caso, cómo debería abordarse.

En la historia de las mentalidades, el interés se ha enfocado, sobre todo, en escribir la historia de los que no tienen voz. En su visión de las cosas, la historia intelectual sería elitista, pues sólo estudia las formas de expresión de la alta cultura. No obstante, se alega, existe un ámbito de representaciones, creencias, simbologías e imágenes, a través de las cuales los estratos inferiores de la sociedad se expresaron, y que merece ser estudiado (Ariés, 1988; Le Goff, 1988; Farge, 2013).

Para Foucault (1992), el problema de la genealogía consiste en estudiar un nexo complejo de sentido donde se entrelazan históricamente tres elementos: una normatividad que controla la conducta humana; unas formas de subjetividad que establecen los lugares y posiciones desde los que el individuo puede constituirse como sujeto social; y un saber que entraña formas de veridicción 
y que se configura en formaciones discursivas. En la articulación de estos tres elementos el autor descubre relaciones de poder, microfísicas y biopolíticas.

Por último, para Koselleck (1989: 300; 2006a; 2006b: 54-55; 2006c; 2006d: 315-316; 2006e: 298-308; 2010a: 88-95; 2010b: 112; FernándezTorres, 2009), la historia conceptual entra necesariamente en relación con la historia social, pues existe una brecha entre la historia acontecida y la historia narrada entre cuyos bordes sólo el concepto puede construir un puente. Esto se debe a que el concepto es simultáneamente factor e indicador del cambio social; esto es, registra las experiencias (indicador) y vehicula las expectativas que transforman el futuro (factor).

En el marco de la historia conceptual, varios autores han tratado de desarrollar los planteamientos de Koselleck, quien ha sido uno de los investigadores que han planteado el problema de manera más diáfana. Dutt y Laube (2013) publicaron una colección de ensayos, que si bien abarca distintas facetas de la teoría de la historia de Koselleck, se ocupa primordialmente del tema del hiato entre historia y lenguaje, al cual se refieren como un tema principal de su carrera académica. Dutt (2008 y 2011) ha enfatizado que la distinción de Koselleck entre las dimensiones de indicador y factor de los conceptos apunta a la función que cumplen los conceptos en la sociedad; es decir, implica la combinación de una semántica histórica con una pragmática histórica.

El trabajo de Hölscher (1991) sobre el concepto de fundamentalismo resulta de sumo interés, porque incorpora tanto la perspectiva de la historia conceptual como la de la historia social (aunque lo que ha de entenderse como tal es bastante amplio, pues el autor aborda tanto acontecimientos clave en la formación del concepto como preguntas sociológicas, por ejemplo: las formas de autoridad que le subyacen, sus vínculos emocionales, entre otros); también en su Nueva Annalistica (Hölscher, 1997 y 2003) se remite a la distinción koselleckiana, aunque no necesariamente de una forma teórica interesante.

A través del estudio de la semántica política y la acción política, Willibald Steinmetz se exhibe como uno de los más destacados continuadores de la obra de Koselleck. No obstante, en su historia de la semántica política, la historia social o lo extralingüístico no es abordado teóricamente (Steinmetz et al., 2012); y en su estudio sobre la relación entre lenguaje y poder, establece una diferencia entre el lenguaje político y el espacio de comunicación política cuyos límites mutan constantemente. Empero, el autor no llega a establecer una conexión teórica entre estos dos ámbitos diferenciados: el de la semántica y el de la actividad política (Steinmetz, 2011). 
Finalmente, Joas y Vogt (2011) traen al público una obra colectiva en cuya cuarta parte se discute el problema del Sattelzeit (tema bastante debatido y centrado en un hito muy estudiado también en su teoría: la temporalidad), pero de tal manera que problematiza la relación entre las estructuras temporales y la semántica del tiempo. En toda esta literatura el tratamiento del problema de la relación entre historia social e historia conceptual, entre lo lingüístico y lo extralingüístico, ha tenido un énfasis predominantemente teórico y/o filosófico, sin que ello haya conducido a un desarrollo teórico de sus premisas. Sólo en algunos casos esta distinción ha intentado llevarse a la praxis historiográfica, pero con un respaldo teórico poco homogéneo y un proceder sumamente pragmático.

Entre todas las escuelas de historia intelectual examinadas, podemos observar que cada una establece una relación entre lo lingüístico (speech act, concepto o discurso) y lo social (que puede adquirir la forma de una institución, relaciones de poder, estructura social o el sencillo discurrir de acontecimientos). Esta convergencia de intereses sobre el tema de la relación entre cambio social y cambio lingüístico puede tomarse como un alegato a favor de profundizar en la investigación teórica sobre el problema.

Definir éste sería el primer paso, y no ha sido cosa fácil. La misma diversidad de perspectivas expuestas con anterioridad pone sobre el tapete la idea de que no existe acuerdo siquiera sobre cómo plantearlo. Esta dificultad se agudiza cuando analizamos la herencia del giro lingüístico, de la cual muchas de estas propuestas teórico-metodológicas, de una forma u otra, son herederas o deudoras.

El giro lingüístico significó un cambio de paradigma en las ciencias sociales (Rorty, 1998). Sobre esto no se suele tener duda (Harris, 2006), pero creemos que no existe la misma seguridad a la hora de señalar la razón. Quizás el giro lingüístico abrió un gran debate dejando aún muchas preguntas por contestar. Sin embargo, a nuestro juicio hay un conjunto de supuestos que se adelantaron en este debate, cuya importancia no puede ser subestimada:

Las ideas no existen, existe el lenguaje. Y el pensamiento no se puede expresar en ausencia de éste, porque son la misma cosa. En este sentido, el lenguaje no es un medio neutral que tendría como función reflejar con precisión una operación cognitiva (un pensamiento o una idea). La expresión lingüística en sí misma es una operación cognitiva. Quizá quien mejor expresó este problema fue Pocock (1985: 2), al redefinir el ámbito de estudio de la historia intelectual, refiriéndola como una historia de los lenguajes, discursos o retóricas. Pareciera que no se acaba de caer en cuenta de la radicalidad del planteamiento. También las ideas de Searle (2009) sobre el lenguaje remiten 
directa o indirectamente a este punto, e incluso lo que Harris (2006: 147) denomina semántica surrogativa.

Los significados de las palabras no se derivan de una correlación entre las palabras y los estados de cosas. Los significados emergen a partir de las formas de uso de las palabras, enmarcadas en determinados juegos de lenguaje (Wittgenstein, 1988).

Los actos lingüísticos son acciones sociales por excelencia. El lenguaje, desde este punto de vista, no es meramente expresión de lo social, sino realización de lo social (Austin, 1971; Searle, 1997).

El problema que emerge de estos supuestos consiste en que no se llegó a una explicación satisfactoria de la función referencial del lenguaje. Se han descrito las funciones de denotación y connotación del lenguaje, tratándose en ambos casos de operaciones que contribuyen a la producción de significados. Pero la tesis de la correlación entre palabra y objeto no llegó a abandonarse del todo, pues, como se ve, eso es lo que implica precisamente "denotación". De esta forma, el obstáculo epistemológico -al decir de Bachelard (2007)que implica hablar de ideas, las cuales, morando en el mundo de las formas, habrían de expresarse más o menos claramente a través del lenguaje, persiste en los supuestos de muchas propuestas teórico-metodológicas, incluso en sus categorías principales, como es el caso de Begriff (concepto) para la historia conceptual (Bödeker, 2002).

Por otra parte, está el tema de que si bien el lenguaje crea relaciones sociales, aquello a lo que da lugar ya no es lenguaje. Por tanto, emerge a la superficie la compleja relación entre lo lingüístico y lo extralingüístico.

¿Cómo definir lo extralingüístico? Según las funciones denotativas o connotativas del lenguaje, lo extralingüístico adquiere dimensiones variadas. Respecto a la denotación, lo extralingüístico se refiere a la "realidad" o a los estados de cosas que se describen lingüísticamente. Desde este punto de vista, la experiencia puede hacernos sentir embargados por una "penuria lingüística” (Gadamer, 2006: 91), pues percibimos que la realidad es mucho más rica de lo que el lenguaje puede expresar. Respecto a la connotación, lo extralingüístico aparece bajo la forma de un excedente de sentido (Ricoeur, 2006); es decir, la connotación permite estirar las formas de uso de una palabra para poder describir lo que antes era indescriptible. Así visto, la connotación desarrollada a través de diferentes tropos retóricos- permite contrarrestar aquella penuria lingüística.

A partir de esa fascinación por lo que hemos denominado con Ricoeur (2006) “excedentes de sentido", Blumenberg (1997 y 2003) desarrolló una teoría de la inconceptualidad. El problema con este planteamiento y aquellos 
afines es que carece de una forma convincente de desplegar la paradoja de la lingüisticidad de lo no lingüístico; es decir, todo lo que existe es traído a la existencia porque se hace palabra, por ende, incluso esas palabras empleadas para connotar lo inasible por el lenguaje son lenguaje, y por tanto, son comprensibles y hechas realidad a través del lenguaje mismo. Es así como se plantea una contradicción, a saber: que lingüísticamente se trae a la existencia la incapacidad del lenguaje para traer objetos a la existencia. De aquí que la pretensión de construir una teoría de la inconceptualidad implique la conceptualidad de lo inconceptual.

Estos razonamientos sobre la connotación nos dejan ver que el lenguaje, como sistema clausurado de signos, es un sistema cognitivamente abierto. Justamente porque el lenguaje no tiene ningún correlato con el mundo, es capaz de producir referencias a partir de sus operaciones internas. Al mismo tiempo, le es posible ampliar sus límites a través de la metáfora, la metonimia, la sinécdoque y otros tropos que explotan la función connotativa de las palabras.

Pero con esto no está resuelta del todo la paradoja de la lingüisticidad de lo extralingüístico. Las paradojas, como nos enseña Luhmann (1996) en varios de sus libros, no se destruyen sino que se ocultan o despliegan, y ¿cómo se hace esto?: introduciendo diferencias. La cuestión sería entonces, ¿qué diferencia aparecería como la más adecuada para realizar esta labor?

Nos parece que tratar el problema al nivel de abstracción planteado (lo lingüístico y lo extralingüístico) no sólo conduce a los dilemas planteados, sino resulta además demasiado indeterminado para la historia intelectual. Es necesario circunscribir el problema a una dimensión que se pueda tratar históricamente. Con todo, como indica Koselleck (2006a y 2003), tal intervención debe tratarse de una operación teórica (meta-histórica) que preceda y oriente la escritura de la historia.

Precisamente ése es el objetivo que nos proponemos alcanzar, sirviéndonos de las herramientas teóricas de la teoría de los sistemas autopoiéticos; y para lidiar con la paradoja mencionada introduciremos la distinción entre semántica y estructura social.

\section{Semántica y estructura social como distinción-guía de la historia intelectual}

Entre todos los enfoques teórico-metodológicos mencionados, aquel que mayor esfuerzo ha dedicado a tratar de establecer un vínculo entre el cambio social y cambio lingüístico ha sido el de Reinhart Koselleck. Para el historiador alemán escribir la historia de un concepto implica amalgamar en una uni- 
dad trazos de sentido que no necesariamente tienen que estar unidos, relacionando usos conceptuales con transformaciones sociales, todo ello bajo el supuesto de que los conceptos son factor e indicador de los cambios sociales y políticos (Koselleck, 2006a; Villacañas y Oncina, 1997). En consecuencia, la conjugación de lo lingüístico con lo extralingüístico es lo que diferencia la historia conceptual de una mera historia semántica (Koselleck, 2004).

Resulta interesante destacar que los planteamientos de Koselleck han influido en el desarrollo de una disciplina que se había mantenido hasta entonces relativamente ajena a los debates mencionados: la sociología del conocimiento. De manera bastante simplificada podemos decir que la sociología del conocimiento ha vivido tres grandes momentos. Comienza su desarrollo con la teoría marxista y alcanza su madurez con la obra de Mannhein (1997), haciendo de su programa el estudio de las relaciones entre clase social e ideología. Vive una reformulación constructivista a partir del trabajo de Berger y Luckmann (2008), quienes proponen la dialéctica entre los procesos institucionales y los universos simbólicos legitimadores. Y finalmente, experimentó un replanteamiento sistémico, guiado por la pluma de Luhmann (1993), quien adelantó como distinción directriz aquella entre semántica y estructura social.

La sociología del conocimiento luhmanniana le debe no pocas cosas a la historia conceptual koselleckiana. Según Stäheli (2000: 186), el sociólogo alemán desarrolla su concepción de la semántica a partir de la historia conceptual de Koselleck, sin dejar de mencionar que no son raras las referencias al historiador en su teoría sistémica. Con Luhmann (1993, 1996 y 2008a), la sociología del conocimiento no se trata ya de averiguar cómo el lenguaje o una ideología sirven para justificar desigualdades sociales o estructuras de poder. La semántica, como la llama Luhmann, no tiene como meta encubrir una relación social objetiva, sino proveer a la comunicación social de un repertorio de sentido generalizado para su constante reproducción. La evolución semántica se encontraría estrechamente relacionada con la estructura social, cuyo grado de complejidad otorgaría o restaría plausibilidad a las variaciones semánticas.

En Luhmann encontramos un desarrollo teórico de las inquietudes planteadas por Koselleck, pero llevadas a un nivel de abstracción que el propio historiador no habría llegado a aceptar. Expresado de una forma muy sintética, el argumento teórico de Luhmann parte del supuesto de que la evolución de la sociedad se explica a través de la evolución de la comunicación. La comunicación se reproduce autopoiéticamente (es decir, que produce y reproduce a partir de sí misma los elementos que necesita para existir) gracias 
a la autorreferencialidad del sentido, pues el sentido constituye la totalidad del mundo social al integrar acciones y vivencias, enmarcando todo lo que puede ser objeto de comunicación.

La comunicación adquiere complejidad en la medida en que el sentido se hace capaz de generalizarse, esto es, en tanto se dispongan de mayores posibilidades para la reproducción de la comunicación. La expansión de las dimensiones de sentido se traduce en el incremento de las posibilidades sociales de acción y vivencia, y, por ende, en el incremento de la complejidad social. Ahora bien, la creación de este excedente de posibilidades de acción y vivencia depende tanto de la semántica como de la estructura social.

La evolución de formas semánticas permite que la comunicación gane mayor capacidad de enlace al existir una provisión de temas, conceptos, lugares comunes, patrones culturales, etc., a los cuales se puede recurrir sin que las posibilidades de negación, contradicción y malentendidos sean muy altas. Mientras, la evolución socioestructural implica que a través de la diferenciación social se pueden multiplicar las posibilidades de acción y vivencia simplemente al restringir un conjunto amplio de posibilidades procediendo selectivamente (Luhmann, 1998a y 1998b). En consecuencia, la semántica y la estructura social son dos caras de una misma moneda: el sentido.

Conviene, sin embargo, precisar el planteamiento teórico de Luhmann introduciendo otra distinción, una que desparadojice también el hecho de que la distinción en cuestión es una distinción semántica. El problema consiste en que el sentido encuentra en el decurso de la evolución sociocultural distintas formas de generalización. Existen formas lingüísticas de generalización del sentido (lugares comunes, conceptos, discursos, campos semánticos y estructuras semánticas), donde el sentido lingüístico se hace significado; y existen formas de generalización del sentido que dependen estrictamente de la estructura social, esto es, de las formas de diferenciación social (segmentos, estratos, centro/periferia y funcional), las codificaciones de los sistemas funcionales (gobierno/oposición para la política, verdadero/falso para la ciencia, ajustado a derecho/ no ajustado a derecho para el sistema jurídico, entre otros), los medios de consecución (el poder, la verdad, el dinero y el amor) y los medios de difusión (escritura, imprenta, radio, televisión y medios electrónicos) (Luhmann, 1998b).

Sobre la estructura social ya ha abundado Luhmann (1998b); no obstante, en cuanto a las formas de generalización lingüística del sentido es menester hacer algunas aclaraciones. Se parte del supuesto de que el significado se produce operativamente, es decir, el significado no es algo ligado a la palabra como parte de su naturaleza, sino que los significados se están produciendo 
constantemente a medida que se emplean las palabras en contextos de sentido enmarcados en sistemas sociales.

Desde este punto de vista, el problema a explicar no es cómo las palabras cambian de significado, sino cómo los significados se estabilizan. La estabilización semántica se produce mediante distintos niveles de generalización, partiendo de los usos más situacionales (enunciados y lugares comunes), pasando por niveles de mayor condensación (conceptos y discursos), hasta llegar a tejer amplias redes (estructuras semánticas y campos semánticos), que también son responsables de la inteligibilidad de los enunciados. Se trata entonces de formas de generalización lingüística que también tienen una constitución autorreferencial, al igual que el sentido (Blanco-Rivero, 2012 y 2013).

Esta diferencia entre las distintas maneras de procesar el sentido nos permite distinguir entre los procesos de reproducción de la comunicación que se basan en el procesamiento de información, y los procesos de generalización lingüística del sentido basados en la producción de significados.

La diferencia entre información y significado reside en que cada uno despliega formas distintas pero complementarias de organizar la relación entre redundancia y variedad (Haken y Portugali, 2015). En la teoría matemática de la información de Shannon y Weaver (1964), se parte del principio de que se puede procesar información sin conocer el contenido semántico de la información transmitida. Esto se hace sencillamente conociendo y manipulando la cantidad de bits (una diferencia binaria) transmitidos. El problema consiste en cómo hacer llegar la información de un punto A hacia un punto B, logrando vencer el ruido del canal de transmisión. Esto se consigue produciendo redundancia; esto es, enviando repetidamente la misma información para reducir el margen de error, lo cual dependerá de la capacidad del canal (Shannon, 1948).

De manera análoga, decimos que un sistema social procesa información en tanto genera la suficiente redundancia para que los bits o distinciones adquieran valor de estructura y puedan ser reutilizados (generalización del sentido), y, al mismo tiempo, suficiente variedad para que las diferencias empleadas puedan inducir cambios en el estado del sistema (reproducción autopoiética).

En el caso del lenguaje -que es también un medio de comunicación-, la redundancia depende del uso iterado de los signos lingüísticos, lo cual conduce a estabilizaciones semánticas (lugares comunes, conceptos, discursos y el espacio o tablero en el que se dan estos movimientos como es el campo semántico); mientras que la variedad depende de la oposición entre palabras, conceptos y discursos, así como por los excedentes de sentido generados por las estructuras semánticas. 
Ahora bien, la formación de significados no tiene lugar en el vacío. Es necesaria la redundancia de sentido provista por los sistemas sociales para hacerse de indicadores contextuales suficientes, que perfilen un conjunto restringido de significados adecuados a la situación para garantizar la inteligibilidad de la comunicación. Por su parte, los sistemas sociales no pueden convertir en estructuras las diferencias si no es por la colaboración del lenguaje. Las redundancias lingüísticas estructuran la capacidad de enlace de las comunicaciones sociales; por lo tanto, juegan un rol crucial en la autopoiesis. En resumidas cuentas, la comunicación social ocurre simultáneamente en dos registros: genera información y produce significados. Se trataría de otra forma de expresión de un planteamiento central en la teoría sistémica de Luhmann (1998b), a saber, la unidad de la diferencia.

$\mathrm{Al}$ traducir estas reflexiones a un esquema analítico que podamos utilizar para la investigación histórica, tenemos que el valor de información de la comunicación se pondera a través de las diferentes estructuras de los sistemas funcionales de la sociedad moderna, a saber: la función (qué problema resuelve el sistema funcional en cuestión para el sistema social global), el código (cómo cada sistema funcional filtra y procesa la información) y el programa (cómo el sistema operacionaliza el código para orientar la reproducción autopoiética de la comunicación) (Luhmann, 2008b: 50-66). Mientras que el significado se procesa socialmente a partir del juego entre distintas formas de generalización del significado: el enunciado, el lugar común, el discurso, el concepto, las estructuras semánticas y los campos semánticos. De la conjunción de ambos ámbitos obtendremos una visión conceptual e histórico-social del problema que estudiemos, en este caso, del totalitarismo.

\section{La historia conceptual y social del totalitarismo}

El tema del totalitarismo representa un caso interesante para poner a prueba nuestro modelo teórico, ya que se trata de un concepto viajero o trasegante, al tiempo que ocupa un lugar destacado en la historia contemporánea.

El concepto de totalitarismo surge en el contexto de entreguerras y se desplaza desde la lucha política hacia la reflexión filosófica y jurídica hasta alcanzar a la ciencia política. Desde allí su carrera política ininterrumpida le hace caer en descrédito en el ámbito científico por su carácter ambiguo y polémico, sobre todo en el contexto de la Guerra Fría. Paralelamente había comenzado su carrera en el mundo literario (ejerciendo gran influencia sobre los medios de masas), en donde entregó testimonios de las vivencias en los países del Este europeo. De esta manera, la literatura contribuyó a darle un 
nuevo hálito al concepto de totalitarismo en el mundo de la ciencia política, para recaer nuevamente en la década de 1980 . Retorna a la arena política, tras un periodo de receso, con los atentados del 11 de septiembre de $2001 \mathrm{y}$, justamente por ello, recobra relevancia en el mundo académico.

Esta es, a grandes rasgos, la historia conceptual del totalitarismo que podemos encontrar en la selvática literatura sobre el tema. Resulta bastante obvio que nos enfrentamos con un concepto nómada que viaja de un campo de experiencia a otro, y que en su incansable vaivén se enriquece cargándose de imágenes, valoraciones y múltiples significaciones. Este tipo de conceptos ha llamado la atención de los historiadores conceptuales, intrigados no solamente por cómo los conceptos viajan a través de distintos mundos culturales, sino también por cómo se mueven entre el tejido de una cultura (Fernández-Sebastián, 2016). Sin embargo, partiendo de una metáfora como la del nomadismo, obtenemos más que nada una provocación que llama nuestra atención, pero con ella no logramos ninguna orientación teórica sobre cómo estudiar este tipo de problemas. ¿Cómo podemos, con otras palabras, describir la trayectoria histórica del concepto a través de la política, la ciencia, la filosofía, el derecho, el arte, entre otros, y cómo cada una de estas visitas ha producido desplazamientos semánticos en el mismo? Una descripción de este tipo es precisamente lo que nos permite el modelo teórico discutido antes.

\section{El totalitarismo y el sistema político}

La política es el contexto de emergencia de los adjetivos total y totalitario, y, posteriormente, del concepto de totalitarismo. Decir esto implica que los usos lingüísticos y la producción de significados discurren bajo el código del sistema político. ${ }^{1}$ Ya plenamente diferenciado y autónomo en el siglo XX, el sistema político filtra y procesa la información a través de un código principal gobernante/gobernado y un código secundario gobierno/oposición (Luhmann, 2002a: 140-145, 151-161).

En este contexto social, en 1923 se le atribuye el primer uso del adjetivo "totalitario" a Giovanni Amendola, quien pretendía desprestigiar al régimen de Mussolini; le seguía un año más tarde Augusto Monti, quien quería denunciar las pretensiones de dominio absoluto, la sujeción de los poderes

1 Luhmann (2008b) no emplea el concepto de codificación de manera análoga a como se ha utilizado en la semiótica y la lingüística. El sociólogo alemán se refiere a códigos binarios invariables en los cuales existe un valor preferencial, que el sistema emplea para operar, y un valor reflexivo, que pone sobre el tapete la contingencia de la selección hecha. En este sentido, el verbo "politizar" denota el proceso por medio del cual el sistema político, a través de su código, le confiere sentido a los acontecimientos ocurridos en su entorno. 
públicos y las Fuerzas Armadas que llevaba a cabo Il Duce. Entre 1926 y 1928 se produce un giro impresionante: aquel adjetivo descalificativo se convirtió en el núcleo identitario del movimiento fascista (Forti, 2008: 35-44; Fuentes, 2006). El totalitarismo fue capaz de sintetizar la pretensión fascista de idealizar al Estado y al individuo como unidad (Gentile, 1928).

Los usos políticos del concepto se encuentran, consecuentemente, enmarcados por el código gobierno/oposición y por eso es observado como un concepto de lucha o como un arma arrojadiza. En la arena política internacional el adjetivo también se convirtió en una frontera política que identificaba amigos y enemigos; así pues, entre 1934 y 1939 el adjetivo totalitarismo sirve para unir bajo un mismo paraguas a liberales, conservadores y socialistas, quienes estaban contra la derecha, mientras que después servirá para separar al mundo democrático y capitalista del mundo socialista y totalitario (Rabinbach, 2006).

Pero el ascenso al poder de movimientos antiestatus quo en muchos países europeos, llegó a significar también que el concepto de totalitarismo adquiría nuevas connotaciones, pues se transformaba en un programa político. Se trataba, en términos bastante generales, de regenerar a la sociedad entera y de crear al hombre nuevo. Y los programas políticos prevalecientes, no ya a nivel estatal, sino también a nivel del sistema total contribuían a moldear la evolución del concepto al conferirle valoraciones positivas y/o negativas según la posición política desde que se lo viera.

Por lo tanto, los programas de "guerra contra el fascismo" durante la Segunda Guerra Mundial y de "guerra contra el comunismo" y de "distensión" durante la Guerra Fría, y hoy en día aquel de "lucha contra el terrorismo", marcaron y marcan subidas y bajones en las frecuencias de uso del concepto y variaciones en las connotaciones que éste adquiría y adquiere (Fuentes, 2006).

El totalitarismo como programa político sirve también a la función del sistema político de mantener la capacidad de tomar decisiones vinculantes colectivas. Esto lo logra al convertirse en una autodescripción tautológica que despliega la paradoja del código al establecer una unidad simbólica entre gobernantes y gobernados (Luhmann, 1996; Blanco, 2016), tal como en la filosofía filofascista de Gentile et al. (1932) o en la tesis alemana del Führer desarrollada por Forsthoff (1933).

\section{El totalitarismo y el sistema de la ciencia}

El código del sistema de la ciencia es verdad/no verdad, mientras que el programa está constituido por las teorías y los métodos. Es claro esperar entonces 
que el despliegue de su función de ganancia de conocimiento (Luhmann, 1992: 167 y ss.), impondrá condicionamientos distintos que otros sistemas a los usos lingüísticos del concepto. La ciencia como sistema está organizada internamente en distintas disciplinas y aquellas que se ocuparon con mayor intensidad del concepto fueron la filosofía, la historia y la ciencia política.

Pero más que las disciplinas en sí, el marco hermenéutico que producirá nuevas significaciones para el concepto dependerá de las denominadas "tradiciones del pensamiento", o mejor, de las estructuras semánticas actualizadas a cada instante. Dos estructuras semánticas son muy importantes con sus respectivos campos semánticos: el campo semántico sociológico con su estructura sociedad/Estado y el campo semántico libertario con su estructura dominación/no dominación.

Como se habrá de suponer, los discursos de tono liberal suelen estar apoyados en la estructura semántica dominación/no dominación. Nos encontramos aquí aquellas primeras críticas académicas al fascismo italiano como la de Lelio Basso (citado en Forti, 2008), las cuales observan la concentración de poderes y la unificación Estado-partido. Por otra parte, la estructura semántica Estado/sociedad muestra una mayor variedad. La encontramos en la formulación de Carl Schmitt sobre el totaler Staat (Forti, 2008), así como en las teorías de la sociedad civil de Adam Michnik y Jacek Kuron (Rupnik, 1991).

Un problema de reflexión que a menudo puso sobre el tapete al totalitarismo como problema de nuestro tiempo fue la modernidad. Así Jules Monnerot, Theodor Adorno y la misma Hannah Arendt partían de los problemas de la sociedad moderna como una fuente o causa de la experiencia totalitaria (Forti, 2008).

Las diferencias entre disciplinas fueron foco de polémicas que incitaron nuevas investigaciones sobre el totalitarismo. Así, por ejemplo, la obra de Friedrich y Brzezinski (1976) puede ser caracterizada por su pretensión taxonómica que se distancia de los enfoques ontologicistas como el de Arendt (Forti, 2008: 86). Pero también hubo alternativas teóricas al problema de los gobiernos no democráticos y se ha ensayado con conceptos alternos como autoritarismo, sistemas de partido único, de partido hegemónico, regímenes burocráticos y, más recientemente, regímenes híbridos (Rabinbach, 2006). De igual manera, el avance en otros campos del saber, como la teoría de la información y la comunicación, ha reavivado la investigación sobre el totalitarismo. Así tenemos la obra de Zdenek Mlynar, quien se inspiró en Karl Deutsch (Rupnik, 1991). En definitiva, la ciencia se ha aprovechado del concepto para impulsar su autopoiesis produciendo teorías y programas de investigación, aunado al hecho de que la actualización política del concepto suele brindar nuevas ocasiones para su reconsideración teórica. 


\section{El totalitarismo y el sistema del arte}

El arte también se ha servido del concepto de totalitarismo para producir nuevas formas y jugar en la frontera entre lo real y lo posible/ficticio; aunque de igual modo la política ha empleado al arte como medio de propaganda ideológica. El código del arte está marcado por la distinción formas potenciales/formas actuales; y esto es porque el arte tiene la función de comprobar que en el ámbito de lo estrictamente posible existe de manera necesaria un orden. Dicho de otro modo, el arte busca hacer perceptibles patrones y regularidades allí donde en principio sólo hay caos o donde sólo existe un objeto determinado y aparentemente simple. Los programas del arte involucran estilos, corrientes, géneros literarios y cinematográficos, entre otros (Luhmann, 2005: 246, 310-327).

El ámbito más prolífico para el desarrollo del concepto de totalitarismo en el arte es la literatura, en particular dentro del género distópico (muchas de cuyas obras fueron llevadas con posterioridad a la pantalla grande). Se reconoce que la primera novela de este género es Nosotros (en 1921) de Yevgeny Zamiatin, quien escribía inspirado en las experiencias de colectivización en la URSS. Le siguen Huxley, Orwell, Koestler, entre muchos otros, aleccionados por las vivencias de las entreguerras y la Segunda Guerra Mundial.

Una de las prestaciones más importantes del sistema del arte al concepto de totalitarismo consiste en haberle dado un impulso para rehabilitarlo en la ciencia. Y esto se logró por el impacto que obras como las de Alexandr Soljenitsin tuvieron en Francia cuando fueron publicadas. Le siguieron muchas otras como las de Zinoviev, Kundera, Fühmann, Alexiévich, entre otras, que seguían plasmando las vivencias humanas del Este de Europa tras décadas de dominación totalitaria. En cuanto rendimientos semánticos se refiere, vale destacar también los íconos culturales que la literatura distópica ha dejado: el Big Brother y la neolengua de Orwell ocupan sin duda este lugar.

Pero los regímenes totalitarios también estimularon la literatura, aunque con fines propagandísticos. En Alemania se les dio empuje a los géneros Völkisch y Blut und Boden, así como a la literatura de guerra. Pero el campo en el que la Alemania nazi se destacó fue en el cine, produciendo gran cantidad de películas que oscilaban entre los temas de la guerra, la moral nacionalsocialista y el antisemitismo. Las artes plásticas y la arquitectura fueron estimuladas tanto por el fascismo como por el nacionalsocialismo, degenerando en una obsesión por lo colosal y la imitación hasta el hastío del neoclasicismo (Silva, 1975; Macciocchi, 1978; Palmier, 1978: 181-183). 
José Javier Blanco-Rivero. Historia conceptual y social del totalitarismo. Una propuesta teóricometodológica

\section{El totalitarismo y el sistema jurídico}

Cuando se habla de totalitarismo, los conceptos de legalidad y constitución suelen aparecer como contraconceptos. No obstante, se suele pasar por alto la existencia de un derecho público totalitario. Ha de tenerse en cuenta que una doctrina jurídica, por más dominante que pueda ser, como la liberal, no es idéntica con el sistema jurídico como sistema social. Aquélla alcanza a formar estructuras que orientan la operación recursiva de las operaciones jurídicas (promulgación de leyes, decisiones judiciales, entre otras), pero siempre queda la posibilidad de que ocurra un cambio estructural en el sistema.

Esas estructuras dentro la doctrina liberal son, por ejemplo, el principio de supremacía de la constitución, el principio de legalidad, el principio de irretroactividad de la ley y el principio de división de poderes. Estos principios establecen cómo han de relacionarse las leyes entre sí y cómo ha de procederse en su aplicación. Pero para la subsistencia del sistema, las estructuras de este tipo son secundarias, lo que interesa es la continuidad de la reproducción autopoiética (Luhmann, 1998a: 332-333) (es decir, que se sigan promulgando leyes y que los tribunales sigan tomando decisiones, y que éstas se vinculen entre sí de una forma u otra).

Para que el sistema jurídico cumpla su función de estabilización de expectativas contrafácticas debe ser capaz de decidir, en atención a su código, qué está ajustado a derecho y qué no. Y el programa que usa para operacionalizar ese código son las leyes vigentes: el derecho positivo (Luhmann, 2002b). Así pues, cuando examinamos la conducta de los regímenes totalitarios podemos palpar que la ley no está ausente, lo que existe es, como lo señaló desde muy temprano Fränkel (1941) para el caso de la Alemania nazi, la coexistencia de un Estado prerrogativo con uno normativo (Forti, 2008: 69). Dicho con otras palabras, el derecho público de los Estados totalitarios está caracterizado por la preeminencia de los estados de excepción, los cuales son un recurso legal a través del cual la ley se excusa a sí misma de regular situaciones que debería regular.

Aunque no existe algo así como una doctrina general del derecho público totalitario, pues en cada caso histórico se partían de situaciones políticas diferentes y de ordenamientos jurídicos distintos (a lo que hay que agregar la pretensión de originalidad de cada empresa totalitaria) (Fuentes, 2006) -véase en el caso español, por ejemplo, Beneyto y Costa (1939) y de Tejada-Spínola (1939)-, sí hay ciertos puntos en común en la praxis jurídica de los totalitarismos. Estos son: reemplazo del principio de supremacía de la constitución por aquel de supremacía del líder; anulación del principio de legalidad (la ley 
no restringe al poder, sino que lo acompaña y realiza); abrogación del principio de separación de poderes y de la independencia del poder judicial -en la Venezuela bolivariana o chavista, por ejemplo, se llegó a hablar del principio de cooperación de poderes (Canova-González et al., 2014: 37-49)-; la inexistencia de los principios de control de los actos del gobierno y de la administración; y por último, la abrogación del principio de la retroactividad de la ley penal (Tapia-Valdés, 1976).

El totalitarismo como concepto y como programa político ha afectado entonces la operación del sistema jurídico, produciendo cambios estructurales e introduciendo una jurisprudencia sui generis en el derecho público de los países que aqueja.

\section{Conclusiones}

La producción de significados no es independiente de los sistemas sociales, pero una vez que un concepto se vuelve patrimonio cultural y escapa a algún ámbito funcional específico (en algunos casos porque nunca estuvo atado a alguno), crea unos nexos semánticos que no tienen correlato con ningún sistema funcional. La semántica se autoorganiza siguiendo patrones particulares de generalización del significado. Pero paralelamente, la actualización de los usos lingüísticos del concepto sólo puede aparecer dentro del contexto de un sistema social y éste tiende a contribuir a inflar su densidad semántica.

Para la mayoría de los sistemas funcionales no es necesaria la precisión semántica para servirse de un concepto, con el objeto de impulsar su reproducción autopoiética; lo importante es su potencial comunicativo al brindar capacidad de enlace. Por consiguiente, los conceptos, discursos o lugares comunes deben traducirse en términos de su prestación de valor informativo para las funciones, los códigos y programas. El único sistema para el cual es relevante la precisión de la significación es el sistema de la ciencia, porque justamente la lógica operativa del sistema lo obliga a refinar las distinciones que emplea para producir conceptos con capacidad analítica y potencial teóricoexplicativo. Y esto es porque su código y sus programas así lo exigen.

Hemos mostrado entonces un modelo en el que podemos incluir y relacionar la historia semántica de un concepto con una dimensión socioestructural, caracterizada en la sociedad moderna por la primacía de sistemas funcionales autónomos. Nótese que en cada sistema funcional la historia semántica del concepto puede ser distinta, pues los usos lingüísticos adquieren significado en el contexto marcado por los códigos y programas. Pero los desplazamientos semánticos tienen una dinámica propia frente a la cual los 
José Javier Blanco-Rivero. Historia conceptual y social del totalitarismo. Una propuesta teóricometodológica

sistemas tienen la potestad de decidir si los toman o rechazan; por lo tanto, se puede observar una dimensión propia de lo semántico en un interactuar complejo con la estructura social.

Es precisamente esta densidad semántica, resultado del proceso descrito, la que nos permite referirnos al concepto de totalitarismo como un concepto fundamental del siglo XX; asimismo, este marco teórico nos hace capaces de comprender con mayor precisión de qué hablamos -cuando decimos con Koselleck- que una palabra se ha transformado en un concepto fundamental.

\section{Referencias}

Ariés, Phillipe (1988), "L'histoire des mentalités", en Le Goff, Jacques, La Nouvelle Histoire, Francia: Editions Complexe.

Austin, John (1971), Cómo hacer cosas con palabras, España: Paidós.

Bachelard, Gaston (2007), La formación del espiritu cientifico, Argentina: Siglo XXI.

Beneyto, Juan y Costa, José-María (1939), El partido. Estructura e historia del Derecho Público Totalitario con especial referencia el Régimen Español, España: Imprenta Heraldo de Aragón.

Berger, Peter y Luckmann, Thomas (2008), La construcción de la realidad social, Argentina: Amorrortu Editores.

Blanco-Rivero, José-Javier (2012), "Hacia una teoría operativa del significado", en Ariadna histórica. Lenguajes, conceptos, metáforas, núm. 1, País Vasco: Universidad del País Vasco. Disponible en: http://www.ehu.es/ojs/index.php/Ariadna [01 de febrero de 2013].

Blanco-Rivero, José-Javier (2013), ;Refórmese el gobierno y los individuos se reformarán! Elementos de una teoría politica venezolana de la emancipación, 1808-1830, Alemania: Dictus Publishing.

Blanco-Rivero, José-Javier (2016), "El poder totalitario: el caso de la Revolución Bolivariana”, en Revista MAD, núm. 34, Chile: Universidad de Chile.

Blumenberg, Hans (1997), "Prospect for a theory of Nonconceptuality", en Blumenberg, Hans, Shipwreck with Spectator. Paradigm of a Metaphor for Existence, Inglaterra: The MIT Press.

Blumenberg, Hans (2003), Paradigmas para una metaforologia, España: Trotta.

Bödeker, Hans (2002), "Begriffsgeschichte als Methode", en Bödeker, Hans Begriffsgeschichte, Diskursgeschichte, Metapherngeschichte, Alemania: Wallstein Verlag.

Canova-González, Antonio et al. (2014), El TSJ al servicio de la revolución, Venezuela: Galipán.

De Tejada-Spínola, Francisco-Elías (1939), La figura del caudillo. Contribución al derecho público nacionalsindicalista, España: Tipografía Andaluza.

Dutt, Carsten (2008), "Funktionen der Begriffsgeschichte", en Müller, Ernst y Schmieder, Falko, Begriffsgeschichte der Naturwissenschaften, Alemania: Walter de Gruyter.

Dutt, Carsten (2011), "Historische Semantik als Begriffsgeschichte. Theoretische Grundlagen und paradigmatische Anwendungsfelder", en Riecke, Jörg, Historische Semantik, Alemania: Walter de Gruyter. 
Convergencia Revista de Ciencias Sociales, núm. 76, 2018, Universidad Autónoma del Estado de México

Dutt, Carsten y Laube, Reinhardt (2013), Zwischen Sprache und Geschichte. Zum Werk Reinhart Kosellecks, Alemania: Wallerstein.

Farge, Arlette (2013), The Allure of the Archives, Estados Unidos: Yale University Press.

Fernández-Sebastián, Javier [coord.] (2016), "El lenguaje político más allá de la política. Hacia una historia de los conceptos sociales, culturales y jurídicos en los mundos ibéricos, siglos XVIII-XX”, en Actas de Congreso, España: Casa de Velázquez-Iberconceptos. Fernández-Torres, Luis (2009), "Un texto fundacional de Reinhart Koselleck: introducción al 'Diccionario' histórico y conceptos político-sociales básicos en lenguaje alemana”, en Revista Anthropos, núm. 223, España: Anthropos.

Forsthoff, Ernst (1933), Der totaler Staat, Alemania: Hanseatische Verlagsanstalt.

Forti, Simona (2008), El totalitarismo: trayectoria de una idea limite, España: Herder.

Foucault, Michel (1992), El orden del discurso, Argentina: Tusquets.

Fränkel, Ernst (1941), Der Doppelstaat, Alemania: Europäische Verlagsanstalt.

Friedrich Carl y Brzezinski, Zbigniew (1976), Dictadura totalitaria y autocracia, Argentina: Ediciones Libera.

Fuentes, Juan-Francisco (2006), “Totalitarismo: origen y evolución de un concepto clave”, en Revista de Estudios Politicos, núm. 134, España: CEPC.

Gadamer, Hans-Georg (2006), "La historia del concepto como filosofía”, en Gadamer, Hans-Georg, Verdad y Método, vol. II, España: Ediciones Sígueme.

Gentile, Giovanni (1928), “The philosophic basis of fascism”, en Foreign Affairs, vol. 6, núm. 2, Estados Unidos: Council on Foreign Relations.

Gentile, Giovanni et al. (1932), "Fascismo", en Enciclopedia Italiana. Disponible en: http:// www.treccani.it/enciclopedia/fascismo_\%28Enciclopedia-Italiana\%29/ [10 de abril de 2015].

Haken, Hermann y Portugali, Jouval (2015), Information Adaptation: The Interplay Between Shannon Information and Sematic Information in Cognition, Alemania: Springer.

Harris, Roy (2006), "How to make History with Words", en Love, Nigel, Language and History. Integrationist Perspectives, Inglaterra: Routledge.

Hölscher, Lucian (1991), "Fundamentalismus und Modernisierung. Sozialgeschichtliche und geschichtstheoretische Bemerkungen zu einem religionspolitischen Kampfbegriff. Vortrag bei der Evangelischen Akademie Oldenburg am 25 Oktober 1991". Disponible en: www. ruhr-uni-bochum.de/lehrstuhl-ng3/publikationen/hoelscher/veroeffentlichungenhoelscher.html [21 de febrero de 2017].

Hölscher, Lucian (1997), "The new annalistic: A sketch of a theory of history", en History and Theory, vol. 36, núm. 3, Estados Unidos: Wesleyan University.

Hölscher, Lucian (2003), Neue Annalistik. Umrisse einer Theorie der Geschichte, Alemania: Wallstein Verlag.

Joas, Hans y Vogt, Peter (2011), Begriffene Geschichte. Beiträge zum Werk Reinhart Kosellecks, Alemania: Suhrkamp.

Koselleck, Reinhart (1989), "Darstellung, Ereignis und Struktur”, en Koselleck, Reinhart, Vergangene Zukunft. Zur Semantik geschichtlicher Zeiten, Alemania: Suhrkamp.

Koselleck, Reinhart (2003), "Über die Theoriebedürftigkeit der Geschichtswissenschaft”, en Koselleck, Reinhart, Zeitschichten, Alemania: Suhrkamp.

Koselleck, Reinhart (2004), "Historia de los conceptos y conceptos de historia”, en Revista Ayer, núm. 53, España: Marcial Pons.

Koselleck, Reinhart (2006a), "Sozialgeschichte und Begriffsgeschichte”, en Koselleck, Reinhart, Begriffsgeschichten, Alemania: Suhrkamp. 
José Javier Blanco-Rivero. Historia conceptual y social del totalitarismo. Una propuesta teóricometodológica

Koselleck, Reinhart (2006b), "Sprachwandel und Ereignisgeschichte", en Koselleck, Reinhart, Begriffsgeschichten, Alemania: Suhrkamp.

Koselleck, Reinhart (2006c), "Die Geschichte der Begriffe und Begriffe der Geschichte”, en Koselleck, Reinhart, Begriffsgeschichten, Alemania: Suhrkamp.

Koselleck, Reinhart (2006d), "Sprachwandel und sozialer Wandel im ausgehenden Ancien régime”, en Koselleck, Reinhart, Begriffsgeschichten, Alemania: Suhrkamp.

Koselleck, Reinhart (2006e), "Begriffliche Innovationen der Aufklärungssprache”, en Koselleck, Reinhart, Begriffsgeschichten, Alemania: Suhrkamp.

Koselleck, Reinhart (2010a), "Fiktion und geschichtliche Wirklichkeit", en Koselleck, Reinhart, Vom Sinn und Unsinn der Geschichte, Alemania: Suhrkamp.

Koselleck, Reinhart (2010b), “Wiederholungstrukturen in Sprache und Geschichte”, en Koselleck, Reinhart, Vom Sinn und Unsinn der Geschichte, Alemania: Suhrkamp.

Le Goff, Jacques (1988), "L'histoire nouvelle”, en Le Goff, Jacques, La Nouvelle Histoire, Francia: Editions Complexe.

Luhmann, Niklas (1992), Die Wissenschaft der Gesellschaft, Alemania: Suhrkamp.

Luhmann, Niklas (1993), "Gesellschaftliche Struktur und semantische Tradition”, en Luhmann, Niklas, Gesellschaftstruktur und Semantik, Alemania: Suhrkamp.

Luhmann, Niklas (1996), "Tautologie und Paradoxie in den Selbstbeschreibungen der modernen Gesellschaft”, en Luhmann, Niklas, Protest, Alemania: Suhrkamp.

Luhmann, Niklas (1998a), Sistemas sociales, España: Anthropos.

Luhmann, Niklas (1998b), Die Gesellschaft der Gesellschaft, Alemania: Suhrkamp. Luhmann, Niklas (2002a), Die Politik der Gesellschaft, Suhrkamp: Alemania.

Luhmann, Niklas (2002b), El derecho de la sociedad, México: Universidad Iberoamericana. Luhmann, Niklas (2005), El arte de la sociedad, México: Herder.

Luhmann, Niklas (2008a), "Sinn, Selbstreferenz und soziokulturelle Evolution”, en Luhmann, Niklas, Ideenevolution, Alemania: Suhrkamp.

Luhmann, Niklas (2008b), Ökologiche Kommunikation. Kann die moderne Gesellschaft sich aufÖßologische Gefährdungen einstellen?, Alemania: Verlag.

Macciocchi, María-Antonieta (1978), "El arte, los intelectuales y el fascismo”, en Macciocchi, María-Antonieta, Elementos para un análisis del fascismo, vol. II, España: Madrágora.

Mannheim, Karl (1997), Ideología y utopia, México: Fondo de Cultura Económica.

Palmier, Jean-Michel (1978), "Del expresionismo al nazismo. Las artes y la contrarrevolución en Alemania 1914-1933”, en Macciocchi, María-Antonieta, Elementos para un análisis del fascismo, vol. I, España: Madrágora.

Pocock, John (1985), "Introduction. The state of the art", en Pocock, John, Virtue, Commerce and History, Inglaterra: Cambridge University Press.

Pocock, John (1987), “The concept of a language and the métier d'historien: some considerations on practice", en Pagden, Anthony, The languages of political theory in earlymodern Europe, Inglaterra: Cambridge University Press.

Pocock, John (1989), "Languages and their implications: the transformation of the study of Political Thought", en Pocock, John, Politics, language and time. Essays on Political Thought and History, Estados Unidos: The University of Chicago Press.

Rabinbach, Anson (2006), "Moments of Totalitarianism", en History and Theory, vol. 45, Estados Unidos: Wesleyan University.

Ricoeur, Paul (2006), Teoría de la interpretación, México: Siglo XXI.

Rorty, Richard (1998), El giro lingüistico, España: Paidós. 
Rupnik, Jacques (1991), "El totalitarismo visto desde el Este”, en Hermet, Guy, Totalitarismos, México: Fondo de Cultura Económica.

Searle, John (1997), La construcción de la realidad social, España: Paidós.

Searle, John (2009), "What is language? Some preliminary remarks", en Ethics and Politics, vol. XI, núm. 1. Disponible en: http://www2.units.it/etica/2009_1/SEARLE.pdf [6 de mayo de 2011].

Shannon, Claude (1948), "A Mathematical Theory of Communication", en The Bell System Technical Journal, vol. 27, núm. 3, Estados Unidos: Bell Labs.

Shannon, Claude y Weaver, Warren (1964), The Mathematical Theory of Communication, Estados Unidos: The University of Illinois Press.

Silva, Umberto (1975), Arte e ideología del Fascismo, España: Fernando Torres Editor.

Skinner, Quentin (1989), "Language and political change", en Ball, Terence et al. [eds.], Political Innovation and Conceptual Change, Inglaterra: Cambridge University Press.

Stäheli, Urs (2000), Sinnzusammenbrüche. Eine dekonstruktive Lektüre von Niklas Luhmanns Systemtheorie, Alemania: Velbrück Wissenschaft.

Steinmetz, Willibald (2011), Political Languages in the Age of Extremes, Inglaterra: Oxford University Press.

Steinmetz, Willibald et al. (2012), Semantiken des Politischen. Vom Mittelalter bis ins 20. Jabrhundert, Alemania: Wallstein.

Tapia-Valdés, Jorge (1976), ¿Neo-autoritarismo o neo-fascismo? Ensayo de interpretación jurídico-institucional, Venezuela: Instituto Latinoamericano de Investigaciones Sociales Fundación Friedrich Ebert.

Villacañas, José-Luis y Oncina, Faustino (1997), “Introducción”, en Koselleck, Reinhart y Gadamer, Hans-Georg, Historia y Hermenéutica, España: Paidós.

Wittgenstein, Ludwig (1988), Investigaciones filosóficas, México: Crítica, Universidad Nacional Autónoma de México.

José-Javier Blanco-Rivero. Doctor en Ciencias Políticas, Universidad Simón Bolívar, Venezuela. Actualmente becario CONICET en el Centro de Historia Intelectual de la Universidad Nacional de Quilmes, Argentina. Líneas de investigación: teorías y métodos de la historia intelectual, teoría de sistemas sociales, semántica y estructura social. Publicaciones recientes: "El poder totalitario: el caso de la revolución bolivariana", en Revista MAD, núm. 34 (2016); "Refórmese el gobierno, y los individuos, ¿ también se reformarán? Venezuela 1808-1830. Un caso de estudio para la teoría operativa del significado", en Ariadna Histórica. Lenguajes, conceptos, metáforas, núm. 3 (2014); ;Refórmese el gobierno y los individuos también se reformarán! Elementos de una teoría politica venezolana de la emancipación, 1808-1830, Saarbrücken: Dictus Publishing (2013).

Recepción: 22 de julio de 2017.

Aprobación: 20 de octubre de 2017. 